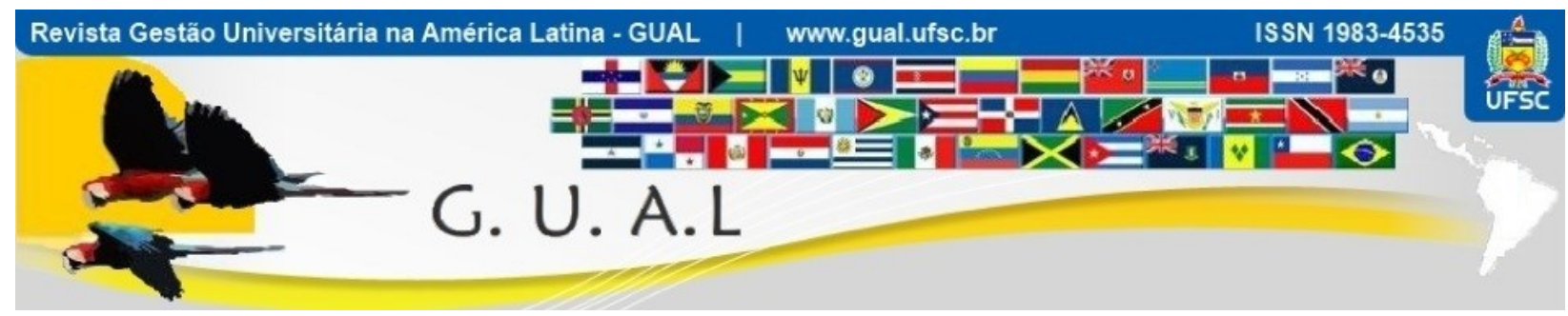

DOI: http://dx.doi.org/10.5007/1983-4535.2014v7n2p286

\title{
EXPANSÃO DO ENSINO SUPERIOR FEDERAL E DESENVOLVIMENTO REGIONAL: O CASO DA UNIVERSIDADE FEDERAL DO PARANÁ NO LITORAL PARANAENSE
}

\section{EXPANSION OF HIGHER EDUCATION AND REGIONAL DEVELOPMENT: THE CASE OF UNIVERSIDADE FEDERAL DO PARANÁ ON PARANÁ'S COAST DEVELOPMENT}

Clovis Wanzinack, Mestre Universidade Federal do Paraná - UFPR clovis_cwb@yahoo.com.br

Marcos Claudio Signorelli, Doutor Universidade Federal do Paraná - UFPR sarcosina@yahoo.com.br

Recebido em 13/agosto/2013

Aprovado em 15/março/2014

Sistema de Avaliação: Double Blind Review

Esta obra está sob uma Licença Creative Commons Atribuição-Uso. 


\title{
RESUMO
}

Este estudo empreendeu descrever e refletir sobre algumas das abordagens adotadas por um campus universitário, criado com vistas à identificação de vulnerabilidades e minimização de problemas de seu entorno, contribuindo com o Desenvolvimento Regional. Com a recente política nacional de expansão do Ensino Superior Federal, foi viabilizada a criação do campus Litoral da Universidade Federal do Paraná (UFPR Litoral), em Matinhos, litoral do Paraná. Para este estudo, foi conduzida pesquisa teórica e social de cunho qualitativo, por meio de análise documental e realização de entrevistas semi-estruturadas com atores sociais (gestores, docentes e coordenadores pedagógicos), que estão vivenciando historicamente o processo de implantação do campus. A pesquisa identificou: patrimônios e vulnerabilidades da região, que justificaram a viabilização do campus neste local; concepções de Desenvolvimento Regional em nível de sustentabilidade e ecodesenvolvimento adotadas institucionalmente; a formação de sujeitos por meio de uma abordagem metodológica diferenciada, que visa instrumentalizálos a intervirem na realidade regional, por meio de abordagens específicas. A consolidação deste estudo permitiu compreender um pouco dos processos da UFPR Litoral, levantar algumas indagações sobre os modos com que esta se propõe a contribuir no desenvolvimento e algumas particularidades de uma proposta em ininterrupta constru-lapidação, que requer a continuidade de estudos e pesquisas.

Palavras-chave: Universidade. Desenvolvimento Regional. Litoral do Paraná. Projeto Político-Pedagógico.

\begin{abstract}
This study aims to describe and reflect about some of the approaches adopted by a university campus, created with a purpose to identifying vulnerabilities and minimizing problems of its surroundings, contributing to regional development. With recent Brazilian National Policy for expanding the Federal Higher Education Network, it was created the Coastal Campus of the Universidade Federal do Paraná (UFPR Litoral) in Matinhos, coast of Paraná's State. For this study, it was conducted theoretical and social qualitative research, through document analysis and conducting semi-structured interviews with social actors (managers, professors and coordinators) who are experiencing historically the deployment process of this campus. Research identified: regional patrimonies and vulnerabilities, justifying the viability of the campus at this location; conceptions of Regional Development related to sustainability and eco-development which are institutionally adopted; student's graduation through a different methodological approach, which aims to instrumentalize them to intervene in regional context, through specific approaches. The consolidation of this study allowed us to understand some of the processes about UFPR Litoral, raising some questions about the ways in which it proposes to contribute to regional development and some features of an ongoing proposal, which requires the continuation of studies and research.
\end{abstract}

Keywords: University. Regional Development. Paraná Coast. Political-Pedagogical Project. 


\section{INTRODUÇÃO}

Para que o Brasil incremente seu desenvolvimento, minimizando desigualdades é de vital importância o investimento em educação, ciência e tecnologia. Nessa conjuntura se enfatiza o papel das Universidades, com seu caráter crítico e inovador, que são comissionadas a contribuir de forma significativa com a promoção do desenvolvimento de uma região por meio da educação, pesquisa científica, extensão e inovação tecnológica. As Universidades são destacadas como Instituições com função crítica e transformadora nas relações de desenvolvimento econômico, tecnológico, político, social e cultural das regiões onde estão inseridas. Essas transformações se expressam nas áreas de pesquisa, no direcionamento de ações de ensino e extensão universitária e na produção de recursos humanos. (THERRIEN E CARTAXO, 1980).

Uma Universidade, em sua dinâmica regional, pode promover influências em contextos econômicos, estimulando crescimento e redução de desigualdades inter-regionais; em contextos sociais, contemplando a melhoria da distribuição da renda e redução da pobreza e também na inovação tecnológica, característica decisiva para o progresso e Desenvolvimento Regional (ALBUQUERQUE 1980).

Com base nesse contexto e compreensão, o Governo Federal instituiu recentemente o REUNI - Programa de Apoio a Planos de Reestruturação e Expansão das Universidades Federais-, responsável por significativo crescimento e expansão do sistema de Ensino Superior Federal no país. A Educação em nível federal passou por um período de estagnação, fruto da falta de investimentos e políticas públicas que fomentassem a ampliação desse campo. Com as últimas gestões federais, esse setor vem sendo impulsionado tanto com a reestruturação e criação de novos campi, de novas Universidades Federais, bem como com a estruturação dos Institutos Federais de Ensino Técnico, Tecnológico e Superior. (SILVA E SILVA, 2011).

Diante dessa Política Nacional de Expansão e Interiorização da Rede Federal de Ensino Superior e cientes de lacunas existentes na área de educação - especialmente em Nível Superior - e dos baixos Índices de Desenvolvimento Humano na região litorânea do Paraná, os gestores da UFPR decidiram ampliar a Instituição, erigindo um campus nesse local, denominado UFPR Litoral.

O Litoral do Paraná enfrenta diversos problemas em termos de desenvolvimento. Destacam-se como principais vulnerabilidades regionais: grande crescimento populacional, 
não acompanhado de crescimento econômico, nem de incremento do panorama social equivalente; precários indicadores de saúde e educação; fragilidades ambientais caracterizadas por tensionamentos entre o uso e ocupação do território e a preservação de delicado ecossistema; entre outras. Um dos fatos marcantes na dinâmica sócio econômica é a questão da sazonalidade dos municípios praianos, que vivem em função da temporada de verão.

Até meados de 2005 a região não possuía nenhuma Universidade, apenas algumas Faculdades isoladas, com pouca oferta de cursos de graduação e de pós-graduação. A UFPR Litoral foi concebida então, não somente para oferecer cursos para uma população menos favorecida e, excluída socialmente, mas acima de tudo, para ser um agente potencializador de desenvolvimento na região (UFPR, 2008a).

Partindo dessa premissa, o desafio estava colocado: Como promover o desenvolvimento por meio da implantação de um campus universitário? Existiria alguma abordagem/proposta pedagógica que poderia contribuir de forma mais incisiva nesse sentido? Quais cursos poderiam colaborar no fomento e promoção de um Desenvolvimento Regional voltado às necessidades e interesses locais?

Movidos por tais indagações, demandas e interesses, foi elaborada a proposta de criação da UFPR Litoral, buscando em uma perspectiva de totalidade atendê-las em solidárias e comprometidas ações coletivas pedagógicas. Totalidade, aqui percebida na compreensão trazida por Boaventura Sousa Santos (2004), ou seja, que a totalidade não coaduna com posições cartesianas e dicotomias, se aproximando de abordagens orientais, com características mais holísticas. Para tanto, foi elaborado um Projeto Político-Pedagógico (PPP) voltado especificamente para UFPR Litoral e de acordo com o Projeto, o trabalho pedagógico a ser desenvolvido e percebido na sua totalidade, deverá ser pautado e regido por princípios que envolvam: "a) o comprometimento da Universidade com os interesses coletivos; b) a educação como totalidade; c) a formação discente pautada na crítica, na investigação, na próatividade e na ética, capaz de transformar a realidade" (UFPR, 2008a, p. 11).

Considerando este conjunto de acepções, foi possível tecer a seguinte indagação: Por meio de quais abordagens e estratégias pedagógicas, a UFPR Litoral tem contribuído na busca de soluções aos problemas da população litorânea do Paraná, na perspectiva de um Desenvolvimento Regional de caráter sustentável. A partir dessa questão, força motriz para a realização deste estudo, buscou-se investigar, dentro dos limites de um trabalho desta natureza, algumas facetas do panorama da recente expansão do Ensino Superior Federal, por 
meio da realização de um estudo de caso, focalizando a implantação de um campus em uma região litorânea do sul do país, ou seja, a UFPR Litoral. Almejou-se visualizar um desenho com alguns dos possíveis benefícios, impasses e desafios dessa estratégia para o desenvolvimento da região litorânea do Estado do Paraná, identificados no seu ainda recente decurso histórico.

Este estudo germinou da necessidade de análise de uma Política Pública que vem sendo implementada nos últimos anos no cenário brasileiro da Educação Superior Federal. A expansão de Instituições Federais de Ensino Superior, em muitos casos associada a um processo de interiorização do sistema e propostas audaciosas de articulação com realidades locais, requer investigações, registros e reflexões aprofundadas. O estudo da UFPR Litoral e sua vinculação com o desenvolvimento do litoral paranaense se configuram em espaço privilegiado para a materialização de um estudo com foco em um panorama regional, que pode ser paulatinamente ampliado a outras realidades análogas, que também são alvo desta Política Pública.

\section{METODOLOGIA}

Foi realizada pesquisa bibliográfica, documental e social, analisando-se qualitativamente alguns dos desdobramentos, após sete anos de implantação do campus da UFPR no litoral paranaense. Foi adotado como referencial teórico-metodológico a estratégia de pesquisa qualitativa, proposta por Minayo et al. (2005), consistindo numa pesquisa de caráter social por meio de entrevistas em profundidade com atores-chave no processo, assim como pesquisa documental, ambas cotejadas por pesquisa bibliográfica.

O propósito da metodologia qualitativa consiste em capturar experiências do mundo social e os significados que as pessoas dão a essas experiências, a partir de suas próprias perspectivas e em situações delimitadas. Tal abordagem intenta documentar o mundo a partir do ponto de vista das pessoas envolvidas no processo. A pesquisa documental levantou informações, documentos e registros históricos, fornecendo subsídios para materializar essa proposta. Foram consultadas diferentes fontes documentais, desde Portarias e Resoluções que designavam a criação do campus Litoral da UFPR, ao PPP da Instituição, passando pelos Projetos Pedagógicos dos Cursos (PPC) e registros sobre a implantação do campus veiculados na mídia. 
Somadas à pesquisa documental, as entrevistas se configuraram em âncoras significativas para a compreensão da realidade estudada. Ao longo da pesquisa foram identificados atores chave no processo em estudo, com os quais foram realizadas entrevistas semi-estruturadas, focando na percepção do interlocutor sobre a experiência. Objetivou-se identificar casos rico-informantes para um estudo em profundidade. Para seleção dos entrevistados atentou-se aos atores sociais com maior tempo de trabalho na Instituição, dandose preferência aos pioneiros; pessoas que exercem ou já exerceram funções de gestão, tais como coordenação de curso, coordenação pedagógica ou direção do campus; pessoas que desenvolvem projetos com a comunidade; e por fim, o envolvimento com o tema de estudo.

Sete pessoas foram identificadas como atores-chave, consistindo em docentes, coordenadores pedagógicos e coordenação do campus. Explanou individualmente os objetivos do projeto, e as entrevistas foram realizadas em local de maior privacidade. Todas entrevistas foram gravadas e transcritas, e para garantir a confidencialidade, os nomes foram codificados numericamente. Após transcrito, o conjunto foi examinado em detalhes, buscando-se identificar as categorias mais significativas e que mais se faziam presentes nos discursos, constituindo análise temática que foi posteriormente confrontada com a literatura. No que tange aos aspectos teóricos, buscou-se aportes na bibliografia a respeito do Desenvolvimento Regional, assim como o papel das Universidades, sua concepção histórica e relação com o Desenvolvimento Regional. Atentou-se também sobre elementos apontados por estudiosos do campo da Educação, sobre a relação entre estratégias pedagógicas e Desenvolvimento Regional.

\section{UNIVERSIDADE E DESENVOLVIMENTO REGIONAL: POSSIBILIDADES DE INTERAÇÕES}

As Universidades desempenham um papel decisivo no desenvolvimento das regiões onde se inserem, assim, vêm recebendo uma atenção crescente nos últimos anos. Guerreiro (2006) argumenta que, tradicionalmente, focalizam-se apenas efeitos multiplicadores que a própria Universidade e a respectiva comunidade acadêmica são capazes de gerar, incrementando mercados locais de consumo, habitação e atração de atividades econômicas no âmbito de prestação de serviços. Todavia, a conjuntura atual revela-se muito mais complexa e intrigante. Para o autor, a bibliografia existente apresenta, em geral, uma visão compartimentada dos potenciais papéis desempenhados pelas Universidades. Um pouco desse 
panorama, se deve à dificuldade de estabelecer procedimentos metodológicos que possam ser aplicados de maneira ampla na produção e sistematização desses dados.

Autores da área de Educação, tais como Paulo Freire, Edgar Morin e Boaventura de Sousa Santos, entre outros, defendem que a educação é um fator decisivo na vida das pessoas, e igualmente são considerados na proposta de Desenvolvimento Regional encampada pela UFPR Litoral. Os autores propõem uma formação emancipatória, de sujeitos autônomos, próativos, sensíveis à realidade e às vulnerabilidades locais, e que proponham ações em prol de sua comunidade. Os modos de como operacionalizar esses pressupostos teóricos na prática se tornam um grande desafio para a comunidade acadêmica da UFPR Setor Litoral. Para isso, foi esboçado um PPP com vistas à formação para atuação no Desenvolvimento Regional, levando em consideração as idéias centrais discutidas até aqui, e que na prática contrastam significativamente com o desenho metodológico convencional, adotado pela maioria das IES.

Parte considerável das Universidades está em um processo de reconstruir o método de ensino através de um processo de aprendizagem centrado no estudante, com experimentação de outros modos de interação entre o educando e o que é aprendido. Na UFPR Litoral, a primeira e mais pronunciada diferença consiste na estratégia de Trabalho por Projetos, por meio de Projetos de Aprendizagem (PA), que se constituem em um dos três eixos curriculares incorporados ao PPP e aos Projetos Pedagógicos de todos os quinze cursos da entidade. Os outros dois eixos curriculares, denominados Fundamentos Teórico-Práticos (FTP) e Interações Culturais e Humanísticas (ICH) também intentam sensibilizar sobre algumas questões relacionadas aos problemas regionais e almejam atuar na busca da resolução, ou ao menos no questionamento e na problematização dessa conjuntura.

Além desses componentes, outros aspectos também buscam estabelecer interfaces entre a instituição e o Desenvolvimento do litoral do Paraná. A própria definição dos cursos a serem ofertados no campus também não foram feitas aleatoriamente. Partiu de uma contextualização de algumas das vulnerabilidades regionais, como saúde, sazonalidade, educação, aspectos sócio-econômicos, mas também converge com a eleição de algumas potencialidades, como turismo, meio ambiente, patrimônio cultural, etc.

As Universidades são capazes de estimular a qualificação social, cultural e desportiva da cidade. Contribui para isso a atração de agentes qualificados e a mistura étnica de estudantes, que criam dinâmicas particulares na cidade e geram oferta de novas atividades. Realçam, consequentemente, o cenário cultural da cidade, pela provisão de eventos culturais e 
desportivos. Apenas para exemplificar, algumas características da UFPR Litoral relativas a este tópico incluem: a construção de um Centro Cultural, inédito no município, contando com Teatro Experimental, Academia de Dança, Hall para Exposições de Artes; a realização de diversos eventos ao longo do ano inteiro, tais como congressos, feiras, competições esportivas, encontros discentes, eventos culturais e artísticos, entre muitos outros.

Fernandes (2007) destaca ainda, que as Universidades podem contribuir para o empowerment e capacitação das comunidades locais. O termo pode ser traduzido para o português como "empoderamento" das pessoas locais, que passam a participar e se apropriar das atividades acadêmicas. Destaca-se nesse sentido, o estabelecimento de parcerias com as comunidades, prestação de serviços às comunidades, realização de atividades de extensão, educação comunitária e inclusão de estudantes pertencentes ao local, que atualmente contabilizam cerca de $75 \%$ de um total de 2 mil estudantes.

Para a definição dos cursos da UFPR Litoral atentou-se aos Arranjos Produtivos Locais (APL), considerando sempre a contribuição de cada curso para o desenvolvimento da região (UFPR, 2008a). Dessa forma, foram concebidos cursos que valorizam, por exemplo, os aspectos ambientais e ecológicos. Nessa área as graduações em Gestão Ambiental e Tecnologia em Agroecologia foram idealizadas buscando desenvolver a região de maneira sustentável, visto que é formada por diversas Unidades de Conservação (UC’s). Já os cursos da área de Saúde e bem-estar social, como Fisioterapia, Serviço Social, Bacharelado em Saúde Coletiva e Tecnologia em Orientação Comunitária buscam melhorar aspectos mais diretamente relacionados à promoção da saúde humana, tanto no âmbito da assistência quanto da gestão, contribuindo para o desenvolvimento humano. A região possui grande apelo turístico, assim cursos como Turismo, Gestão e Empreendedorismo e Gestão do Esporte e Lazer foram criados, buscando fomentar estratégias e ações nessa área, pensando-se principalmente em alternativas para extrapolar a temporada de verão. As licenciaturas em Artes, Ciências e Linguagens e Comunicação, vêm a somar principalmente na área educacional, formando pessoas qualificadas para atuação nos diferentes níveis de ensino em seus respectivos campos de atuação. O Curso de Informática e Cidadania tem uma proposta bastante audaciosa, que objetiva incorporar a cidadania ao campo da Informática, não promovendo um ensino estritamente tecnicista, mas concebendo essa área de maneira socialmente comprometida. Já cursos como, Gestão Pública e Gestão Imobiliária têm como preceitos principalmente formar uma massa crítica que pense, planeje e implemente ações 
relacionadas às questões de gestão do território e de políticas públicas, sempre com um olhar interdisciplinar nas e das diferentes áreas.

Muitas repercussões da busca e efetivação desses objetivos podem ser observadas. Como dados informativos, a titulo de ilustração, já que este trabalho não tem o intuito de cartografar todas as ações desenvolvidas pela Instituição, pode-se destacar, a parceria entre a UFPR Litoral e a Prefeitura de Matinhos que viabilizou no município: a implantação uma Clinica Escola de Fisioterapia que realiza gratuitamente cerca de 1000 atendimentos mensais à população da região; a implantação de um laboratório municipal de Análises Clínicas e Laboratoriais; a viabilização de um Centro Cultural, que promove atividades artísticas e culturais, direcionadas desde as crianças até os idosos, além de espetáculos e eventos culturais gratuitos à população; o Programa de Formação Continuada de professores da Rede Pública, por meio de semanas pedagógicas e cursos de extensão, aperfeiçoamento e especialização.

Entretanto, ainda são parcos os estudos sobre a avaliação dessa política educacional, que assim como resultou na implantação do campus da UFPR Litoral em 2005, originou diversas outras expansões em outros locais do país.

\section{ESTRATÉGIAS PEDAGÓGICAS E DESENVOLVIMENTO REGIONAL}

O mais importante a considerar neste trabalho, não é julgar se a Universidade está atingindo ou não seu objetivo institucional, mas pensar a respeito de quais estratégias pedagógicas e por meio de quais metodologias vem buscando seus intentos. Quais os diferenciais dessa Instituição, que propõe olhar as questões sociais no qual se percebe circunscrita, almejando contribuir com o desenvolvimento de seu entorno? O que referem os documentos que embasam essa proposta a respeito dessa particularidade? Qual o arcabouço teórico-metodológico a sustentar tal proposta? O que os atores que estão vivenciando esse processo relatam sobre o assunto? Quais os principais êxitos e desafios destacados por esses atores até o momento? Essas perguntas norteiam esta seção de resultados.

O PPP da UFPR Litoral, por meio de estratégias como "Trabalho por Projetos", favorece a interação das atividades formativas da Instituição com a comunidade e com a realidade regional. Professores, técnicos e estudantes, por meio de fases sucessivas de conhecimento, (compreensão, proposição e ação), desenvolvem Projetos de Aprendizagem e de docência, relativos aos desafios observados na região e em sintonia com a população local. Constroem dialeticamente uma "profissionalidade" proativa nos educandos, que prima pela 
responsabilidade cidadã nas comunidades envolvidas com a proposta. (UFPR, 2008b, p.3-4). Um dos entrevistados sustenta nesse sentido:

“Ao pensar a UFPR Litoral como um agente de desenvolvimento, seria fundamental
inserir a população local no processo, mas não apenas visando "capacitá-los" ou
"treiná-los" para serem utilizados como mão-de-obra durante as temporadas de
verão, mas sim para que se tornem sujeitos emancipados e
protagonistas."(Entrevistado n ${ }^{\circ}$ 04)

Percebe-se nesse relato, que um dos intuitos da Instituição é o empoderamento de uma população que permaneceu por muito tempo marginalizada e excluída socialmente. A partir desse recorte pode ser visualizada uma conjunção de estratégias distintas, que juntas intentam atingir o desafio institucional da UFPR Litoral. São elas: o reconhecimento da realidade regional, a integração da educação pública em diferentes níveis, e a proposta de trabalho por projetos. Tentar-se-á explorar um pouco de cada uma dessas estratégias, que se articulam em torno do objetivo maior de Desenvolvimento Regional.

Primeiramente cabem algumas considerações a respeito do quesito "reconhecimento da realidade regional". Diversos cursos desse campus, em seus PPC, contemplam módulos em torno do "Reconhecimento Regional" ou "Reconhecimento do Litoral", variando a nomenclatura, conforme o currículo do Curso. Tais módulos são trabalhados no início dos Cursos, geralmente durante o primeiro semestre, para que estudantes tenham contato com a realidade da região. São aprofundados os conhecimentos a respeito das principais vulnerabilidades e potencialidades locais, envolvendo a sensibilização de distintas áreas, como a ambiental, sócio-econômica, cultural, entre outras; uma vez que todos esses fatores podem ser determinantes no processo saúde-doença. Em algumas graduações, como Informática e Cidadania, Saúde Coletiva, Tecnologia em Orientação Comunitária, o módulo Reconhecimento do Litoral é realizado com turmas mistas, agregando estudantes de diversos campos, objetivando o diálogo entre as distintas profissões, pensando-se sempre num ideal de interdisciplinaridade.

A partir do reconhecimento das questões locais, com foco nas vulnerabilidades, os estudantes são instigados a desenvolverem seus Projetos de Aprendizagem (PA), que ocupam $20 \%$ da carga horária de todos os cursos da UFPR Litoral. Todos os PPC reservam o espaço das sextas-feiras para esse eixo curricular, que tem como fulcro o trabalho por projetos. A esse eixo somam-se ainda outros dois eixos: as Interações Culturais e Humanísticas (ICH), 
que ocupam o espaço das quartas-feiras; e os Fundamentos Teórico-Práticos (FTP) que ocupam o espaço dos outros dias. Cada um desses eixos será descrito com mais detalhes.

Antes de passar para essa discussão, merece ser explanado o quesito articulação e integração entre os diferentes níveis da Educação Pública. Com o propósito de contribuir com a região com uma distinta concepção de Universidade que articula todos os níveis educacionais, da Educação Infantil à Pós-graduação, foi sendo concebido o Projeto Educacional que integra e articula as Políticas Públicas com os diferentes agentes educacionais (UFPR, 2008b). Nesse aspecto, emergem o Grupo de Educação Pública e os docentes articuladores interinstitucionais, que fazem o elo entre a Universidade e cada uma das respectivas Secretarias de Educação dos Municípios da região.

Dentre as atribuições destes representantes estão: (a) representar a Instituição na comunidade educacional regional; (b) subsidiar as ações pedagógicas propostas pelo Grupo de Educação Pública nos municípios; (c) conduzir levantamentos, estudos, pesquisas e ações educativas nos municípios do Litoral do Paraná; (d) articular contatos junto às Prefeituras Municipais, bem como demais órgãos públicos, privados e do terceiro setor considerados importantes para o desenvolvimento da educação pública da região (atribuições em discussão e construção). Desse modo, os articuladores fazem a ponte entre Universidade e Secretarias Municipais de Educação da região, agregando os diferentes níveis educacionais. Além de projetos especiais, como por exemplo, as Semanas de Formação Pedagógica, muitos dos projetos propostos por estudantes e também por professores, somados aos projetos demandados pelas prefeituras, são viabilizados por meio dessa articulação. De acordo com Brizolla (2010) tais projetos têm em comum a característica de atuação direta na Educação Pública da região, imbricando em seus objetivos e metodologias de desenvolvimento tanto ações de pesquisa quanto de ensino e de extensão.

Conforme aponta Signorelli et al. (2010), a partir da definição do compromisso da UFPR Litoral em potencializar o Desenvolvimento Regional do Litoral do Paraná, e com a ciência de que apenas democratizar o acesso à Universidade, garantindo que as pessoas daquela região frequentassem cursos universitários não seria suficiente para suprir essa expectativa, atentou-se sobre a necessidade de repensar as próprias estratégias pedagógicas. $\mathrm{O}$ paradigma tradicional de ensino, centrado no conhecimento fragmentado em disciplinas e na figura do docente, detentor do saber e transmissor de conhecimentos, em currículos engessados e focados no tecnicismo das profissões, em departamentos que não dialogam entre 
si, bem como profissões que não se comunicam, vem demonstrando ser um modelo ineficiente e colonizador, que não iria atender os pressupostos e encaminhamentos teóricopedagógicos da proposta em desenho e construção.

Não caberia deixar de refletir sobre uma concepção político-pedagógica vinculada diretamente ao compromisso institucional com o desenvolvimento. Era necessário que a comunidade universitária dialogasse com a comunidade local na busca de soluções pensadas e executadas conjuntamente para redução dos problemas regionais. Assim, foi imprescindível a fundamentação a partir de um referencial teórico-metodológico, que contemplasse essa conjuntura.

Neste contexto, Freire (1996) acrescenta aspectos relacionados à formação de estudantes com vistas à autonomia, emancipação e compromisso em processos de coletividade, onde estes se percebem como sujeitos construtores do conhecimento e interventores sociais $d a$ e $n a$ história. A autonomia na visão de Morin (2010, p. 118) não é mais um liberdade absoluta, emancipada de qualquer dependência, mas uma autonomia que depende de seu meio ambiente seja ele biológico, cultural e ou social.

A estruturação pedagógica de aprendizagem baseada em Trabalho por Projetos vem ao encontro dos pressupostos colocados por esses autores. Por meio da autonomia, o estudante pode optar pelo tema de seu projeto, conduzindo-o de modo comprometido com a coletividade envolvida em seu projeto, buscando as interações e diálogos possíveis entre o sujeito e o meio. A organização das atividades formativas, incluindo a condição dos projetos, se dá em três fases: 1) conhecer e compreender, 2) compreender e propor e 3) propor e agir.

Os Fundamentos Teórico-Práticos (FTP) se organizam em módulos, que são meios e não fins no processo de formação do futuro profissional. Com rigor científico e contextualização com os desafios reais que o estudante vai enfrentando, os fundamentos são organizados de forma consonante com as diferentes etapas da Proposta Pedagógica, buscando atender tanto as diretrizes curriculares de cada profissão, como propiciar os saberes necessários à execução dos projetos de aprendizagem. (UFPR, 2010).

Os FTP's são desenhados por equipes interdisciplinares de docentes nas respectivas Câmaras de cada Curso, que integram a Instituição. Neste eixo não caberia, o excesso de conteúdos, nem conteúdos desconectados uns dos outros. Mas sim conteúdos interligados e que fizessem significado para o estudante, despertando o seu interesse em apreender. Dessa maneira, as "disciplinas" são agregadas em módulos temáticos que articulam o conhecimento 
de maneira integrada. Os módulos, diferentemente de disciplinas tradicionais, são compostos por equipes de professores oriundos de distintas áreas de formação, buscando uma interação entre os diferentes campos do saber. São pensados, idealizados e ministrados conjuntamente também, utilizando-se especialmente metodologias ativas de aprendizagem.

Nas Câmaras dos Cursos, além da participação dos professores, os acadêmicos e técnicos-administrativos foram ganhando espaço. Os acadêmicos que hoje têm uma discussão entre seus pares e com os docentes chegaram à Universidade trazendo também sua construção histórica e um forte apelo familiar e social. Obviamente, também carregam consigo constructos sociais e políticos que possibilitam o diálogo com os fundamentos do PPP, reinterpretados à luz da compreensão dos professores, com maior ou menor pressão do meio social e geográfico onde estão inseridos. Nesses diálogos, os projetos pedagógicos dos cursos são (re) desenhados e, conforme ensina Vieira Pinto (1960) apud Fagundes (2009), é legítimo no momento em que exprime a "consciência coletiva e revela os seus anseios" (p. 35), emergindo das massas e jamais sendo imposto. Essa construção coletiva supõe a presença de quadros da Universidade como fomentadores da discussão na perspectiva emancipatória que se propõe o PPP, de maneira conjunta entre professores, estudantes, funcionários e comunidade local.

Com relação ao $3^{\circ}$ eixo curricular, além dos FTP e PA, o eixo das Interações Culturais e Humanísticas - as ICH- consiste em outra interface da formação profissional dos estudantes com a realidade e as comunidades locais. As ICH têm por objetivo contribuir para a formação humana e trata-se de espaços diferenciados onde a aprendizagem acontece através de reflexões e vivências sobre os saberes científicos, culturais, artísticos, populares, pessoais entre outros. Nas ICH os estudantes de diferentes cursos se agregam em grupos mistos, se conhecem, aprendem juntos, participam semanalmente durante toda sua formação de atividades que despertam seu interesse e compreensão sobre si mesmo, sobre as relações humanas e sobre o mundo. Alguns exemplos de atividades de ICH que já foram realizadas: Literatura em Ação, Biopsicologia, Gastronomia, Qualidade de Vida através da Dança, Xadrez, Violência e Cidadania, Gênero e Diversidade Sexual, Capoeira, Escola de Surf, Commédia Dell' Art, A construção Sócio-espacial do Olhar, Educação Popular, Manejo de Trilhas, Maricultura no Paraná, Meliponicultura, "Você é o que come", Teatro e Comunicação, Arte e Reciclagem, Conhecer o Modelo Agroecológico, O campus Litoral na Comunidade da Ponta Oeste da Ilha do Mel, Noções de Ciência Política, Técnica Vocal e 
Coral, e muita outras. O currículo das ICH está em permanente "movimento", pois sempre estão sendo (re)criadas novas atividades todo semestre a partir dos interesses e do protagonismo dos estudantes, técnicos e professores. (UFPR, 2010).

O eixo das ICH foi idealizado com base em aportes de Humberto Maturana, que é criador da teoria da autopoiese e da Biologia do Conhecer, junto com Francisco Varela. Tais autores são propositores do pensamento sistêmico e do construtivismo radical (Maturana e Varela, 2001). Em síntese, sua teoria e forma de pensar propõem o fim do dualismo mentecorpo, identificando o processo do viver com o processo cognitivo. Esses autores enfatizam o processo de conhecimento construído a partir das interações, destacando o resgate das emoções, num processo de (re) valorização das mesmas. Essa teoria emerge dentro de uma conjuntura atual que tem escondido as emoções, por ir contra a razão. Maturana coloca o ser humano como um ser vivo em particular e que o amor é a emoção que o sustenta, sendo fundamental na aceitação do outro. Partindo dessa premissa, atentou-se à fragmentação existente em currículos tradicionais, como no caso das disciplinas das áreas técnicas e aplicadas que não dialogam com as disciplinas das áreas de ciências humanas, como psicologia, antropologia, filosofia ou sociologia. Outro aspecto significante colocado pelos autores é a valorização das emoções. Nesse sentido, refletiu-se sobre o extremo tecnicismo que as carreiras acadêmicas vêm direcionando sua formação. Esse tecnicismo acentuado muitas vezes deixa de lado os aspectos subjetivos do ser humano, que são fundamentais em profissões que lidam com seres humanos. Assim, as ICHs compõem o mapa curricular ao longo de todo o curso, correspondendo a $20 \%$ da carga horária dos cursos. Neste espaço curricular, estudantes dos diferentes cursos da UFPR Litoral participam juntos, independentemente de seus cursos, ou seja, num espaço intercursos, de atividades como oficinas, debates, vivências, saídas de campo, práticas, entre outras. Tais atividades permitem uma sensibilização para as questões que Maturana e Varela colocam, estimulando a interação e a interprofissionalidade. Em termos práticos, as ICH possuem um espaço na agenda semanal da UFPR Litoral: ocorrem todas as quartas-feiras. Assim, dentro de um cardápio de diferentes atividades, o estudante pode optar por aquela que lhe desperta maior interesse, independente de sua carreira de graduação. Nesse espaço, a interdisciplinaridade permeia todo o processo, haja visto que docentes e discentes são oriundos de diferentes áreas e carreiras.

Somados às ICH e aos FTP, o terceiro eixo curricular da UFPR, que também revela interfaces com a minimização de problemas regionais é o eixo de Projetos de Aprendizagem 
(PA). O desenho curricular que se fundamenta no Trabalho por Projetos permite que o estudante construa o seu conhecimento de maneira integrada com diversas áreas do conhecimento. Assim, além dos FTP específicos de cada curso, o estudante organiza seu cotidiano tendo também os espaços semanais para as ICHs e para dedicar-se ao PA. O estudante é incentivado a perceber criticamente a realidade, compreender os diversos aspectos que a estruturam e a estabelecer ações integradas entre a Instituição e a comunidade. Tais ações podem contemplar uma diversidade de possibilidades, desde que alie o aprofundamento metodológico e cientifico a uma transição para o exercício profissional. $\mathrm{Na}$ proposição do projeto o estudante antecipa e vivencia a autonomia do seu exercício profissional, sob mediação docente.

Ao trabalhar com PA ou situações problemas nas escolas, foca-se na realidade, direcionando a energia em busca de soluções de problemas, ao mesmo tempo em que se realiza um processo de imersão concentrada na construção de conhecimento. Ao estabelecer o propósito do projeto, seus objetivos, o problema a ser pesquisado e o conjunto de certezas provisórias e dúvidas temporárias que orientarão o movimento do pensamento e que revelam os sistemas de significação, busca-se na verdade, tentar pôr ordem na consciência. Direcionase melhor as atenções e intenções, esclarecendo a forma como se pretende buscar, localizar, selecionar as informações na tentativa de encontrar a solução ao problema ou desafio colocado. Um PA ou uma situação problema envolve a definição de metas claras a serem alcançadas com a sua realização. Essas metas estão relacionadas aos desafios ou situações que exigem uma certa direção e requerem um sistema de ações relevantes, que, por sua vez, exigem determinadas habilidades e competências para a sua consecução. (MORAES, 2003).

Muitos dos PA desenvolvidos pelos estudantes, são provenientes de temas abordados nos módulos de Reconhecimento do Litoral, do início do curso, ou ainda a partir de seus próprios anseios com relação a temas que lhes despertam o interesse. Além dos PA, desenvolvidos por discentes com mediação docente, outros projetos também são desenvolvidos na comunidade universitária, por todos os atores que compõem a UFPR Litoral. Destacam-se os projetos desenvolvidos pelos docentes e técnicos, em que discentes também participam: projetos de pesquisa, projetos de ensino, projetos de extensão, além dos próprios projetos institucionais implementados pela UFPR, tais como os projetos em parceria com a Rede Pública de Educação, já explicados anteriormente. 
Outro aspecto significativo é a conexão com a realidade e com o contexto global, fato defendido e discutido por Morin (2010). Dessa maneira, o trabalho por projetos é um elemento central nas estratégias pedagógicas da UFPR Litoral com vistas ao desenvolvimento local, e de acordo com a metodologia de trabalho por projetos proposta por esses autores, estudantes, docentes e a Instituição são corresponsáveis pelo desenvolvimento de projetos estabelecidos em diálogo com a comunidade litorânea, atentando-se aos problemas regionais e que compreendam a tríade ensino-pesquisa-extensão. Assim, numa via de mão dupla, ao mesmo tempo em que estudantes e docentes aprendem, produzem conhecimento e promovem atividades de pesquisa e extensão, a comunidade se beneficia por meio de projetos que se transformam em ações com intuito de minimizar os desafios encontrados no cenário local.

Dessa maneira, os espaços curriculares da UFPR Litoral como os PA e ICH e alguns dos FTP são realizados de modo interdisciplinar em atividades intercursos, sem a segmentação por cursos tipicamente assumida nas atividades formativas em Universidades mais tradicionais. A realização de PA, assim como a realização de atividades culturais e humanas em pequenos grupos com docentes oriundos de diferentes áreas do saber, possibilita uma reflexão e ação complexas se apropriando de elementos da teoria da complexidade de Edgar Morin (1996).

A estratégia de desenvolvimento de projetos é uma forma "complexa" de conceber o aprendizado. Esta envolve o estudante, o professor, os recursos disponíveis, inclusive novas tecnologias, e todas as interações que se estabelecerem nesse ambiente, denominado ambiente de aprendizagem. Tal ambiente é criado para promover a interação entre todos os seus atores, propiciando o desenvolvimento da autonomia do estudante e a construção ativa de conhecimentos provenientes de distintas áreas do saber, por meio da busca de informações significativas para a compreensão, representação e resolução de uma situação-problema.

Moraes (2003) realça a necessidade de desenvolver um pensamento complexo que facilite o encontro de soluções a problemas tão complexos como aqueles envolvidos nas questões relacionadas à violência, à globalização, questões ecológicas, humanas, enfim, a própria tessitura da vida.

Obviamente, muitos são os desafios inerentes a essa proposta e nem todos poderão ser trazidos e detalhados aqui. Cabe destacar, de acordo com a locução dos entrevistados: a falta de experiências semelhantes, que sirvam de parâmetros para essa experiência; a dificuldade de algumas pessoas para se adaptarem ao formato dessa empreitada, bem como o desafio 
logístico de organizar tais atividades, que acabam gerando certa resistência pois deslocam os sujeitos de suas zonas de conforto; a preocupação com a sustentabilidade da proposta, pois pode ser apenas uma estratégia da gestão atual, não sendo incorporada às futuras gestões; a pouca efetivação de alguns propósitos, ficando muitos elementos apenas restritos aos discursos e ao campo das intencionalidades; e ainda o desafio de integração da equipe envolvida, e de uma equipe de docentes, técnicos e educandos com domínio metodológico e teórico que viabilize a idéia emancipatória.

Já em relação aos êxitos, embora alguns entrevistados ainda considerem precoce o momento para se pensar em êxitos, foram relatados como aspectos significativos: o ingresso de uma média de 70 a $80 \%$ de estudantes oriundos do Litoral do Paraná nos últimos concursos vestibulares; a vinda de pessoas de fora para compor o grupo, principalmente docentes e técnicos, visto como um aporte para novas idéias, novos modos de pensar, que contribuem para a dinamização do local; o ineditismo da proposta, que busca incorporar a dimensão Desenvolvimento Regional; entre outros.

Apesar de limitações e alguns êxitos colocados por diversos interlocutores, observa-se que tanto o texto dos documentos institucionais consultados, quanto as narrativas das pessoas entrevistadas, parecem fazer um chamamento, um conclame para que a referida comunidade universitária (e aí incluem-se corpo discente, docente e técnico administrativo) venha a despertar-se e engajar-se no desenvolvimento de ações (por meio de ICHs, PAs e FTPs) que minimizem vulnerabilidades no contexto regional.

A adoção de tais estratégias pedagógicas e o diálogo com diferentes autores constituise em debate fecundo e extremamente extenso. No espectro deste artigo, cabe salientar que o conjunto formado por estes pressupostos teóricos vêm guiando a estruturação do PPP da UFPR Litoral, os PPC, as estratégias metodológicas e os processos de ensino-aprendizagem. É possível e esperado, que esses dispositivos engendrem a formação de sujeitos conscientes de seu papel no contexto regional, podendo resultar em médio/longo prazo na constituição de um coletivo de pessoas comprometidas com a proposta institucional, ou seja, ações imediatas, progressivas e permanentes que tenham como horizonte o desenvolvimento do litoral paranaense.

Portanto, estudar esse cenário, que compreende aportes teóricos e empíricos que vêm materializando uma proposta voltada ao desenvolvimento local através da estruturação de um campus universitário com estratégias metodológicas diferenciadas, constitui-se em uma 
oportunidade privilegiada para sistematizar historicamente algumas informações, reflexões, contribuições em curso, assim como sinalizar desafios e possibilidades envoltos na expansão/construção do Ensino Superior Federal e sua relação com o Desenvolvimento Regional na região litorânea do Paraná.

\section{CONSIDERAÇÕES FINAIS}

A partir da proposta de uma Instituição, nascida fruto de recente política nacional de expansão do Ensino Superior Federal e que foi concebida particularmente para promover o desenvolvimento de seu entorno, atentou-se neste trabalho a direcionar o olhar para o estudo de um caso específico. Objetivou-se compreender por meio de quais abordagens e estratégias a UFPR Litoral vêm atuando no sentido de contribuir com a resolução de problemas do e no litoral paranaense. Para tanto, foi estabelecido um diálogo com estudiosos, que pesquisam os temas desenvolvimento, Universidade e educação, buscando algumas das interfaces entre esses assuntos. Também se pesquisou algumas peculiaridades do contexto regional do litoral paranaense, com foco em determinadas vulnerabilidades, que somados à pesquisa de campo, constituíram elementos significativos para refletir sobre o objeto de estudo. Foi adotada como metodologia, além de pesquisa teórica, a pesquisa de campo de caráter qualitativo, que consistiu em pesquisa documental e entrevistas semi-estruturadas com atores que estão vivenciando o processo no decurso histórico.

Portanto, é possível assinalar com este estudo que, desde sua primeira idealização em 2001, passando pela implantação, que iniciou em 2005, até o estágio atual de sua implementação, em 2013, muitas são as possibilidades e os desafios em torno da proposta. Não é intento aqui elencar, tampouco fazer juízo de valor sobre os feitos, mas refletir sobre algumas facetas do processo, que de modo pioneiro em uma Instituição de Ensino Superior no país, busca alinhar suas estratégias de ação em torno, com e para o desenvolvimento da região onde está inserida.

O Litoral do Estado do Paraná é uma região de rico patrimônio histórico, cultural e ambiental. Entretanto, possui dinâmica socioeconômica precária, como revelam alguns indicadores (IDH, IDEB, etc). Com base na análise de tais vulnerabilidades, foi possível compreender a justificativa de abrir o campus da UFPR no Litoral do Paraná, e não em qualquer outra região do Estado. O objetivo institucional não foi meramente criar vagas de 
educação superior, mas sim conceber uma Instituição que fomentasse a minimização desses problemas e contribuísse com o desenvolvimento da região.

O desenvolvimento de um local não se restringe apenas ao incremento econômico ou industrial, mas agrega distintos elementos, desde ambientais até culturais, objetivando a preservação de recursos para as gerações futuras. Para que se construa um desenvolvimento em uma determinada região, há uma necessidade de se criar uma "autonomia endógena", que encoraja a população local na construção participativa de novas estratégias de desenvolvimento, em que a própria população se torne parte desse processo, juntamente com outros atores governamentais, para uma melhor condução a uma trajetória de desenvolvimento local.

Para atingir tal intento, a UFPR Litoral foi concebida por meio de um PPP específico, capaz de agregar tais perspectivas de desenvolvimento, e que visa não apenas proporcionar a formação de pessoas para o mercado de trabalho, em um local com dinâmica marcada pela sazonalidade. Esquadrinhou-se uma proposta, que buscou referenciais em autores como Paulo Freire, Edgar Morin, Boaventura de Sousa Santos, entre outros, que objetivam a formação emancipatória de sujeitos autônomos, pró-ativos, sensíveis à realidade e às vulnerabilidades locais, e que proponham ações em prol de sua comunidade.

Nesse sentido, podem ser destacadas de modo sucinto algumas das estratégias e metodologias em vigência na UFPR Litoral, que caminham nessa direção, e que foram abordadas ao longo do texto. A primeira e mais pronunciada pelos interlocutores e pelos documentos analisados é a estratégia de Trabalho por Projetos, incorporada ao PPP e aos PPC de todos os quinze cursos da entidade, materializada nos currículos, por meio do eixo PA, ocupando o espaço das sextas feiras. A partir do reconhecimento de questões regionais, nos módulos de Reconhecimento do Litoral, os estudantes são instigados a desenvolver seus PA mediados por docentes, agregando a tríade ensino-pesquisa-extensão e com vistas à proposição de ações nas comunidades, na busca da minimização dos problemas regionais. $\mathrm{O}$ trabalho por projetos também evidencia os projetos desenvolvidos por docentes e por técnicos, assim como os projetos institucionais, sempre na busca de envolvimento de acadêmicos dos diferentes cursos, proporcionando uma formação interdisciplinar e emancipatória, conectada com a realidade do entorno e visando desenvolver os aspectos supra-citados, como autonomia, empoderamento, protagonismo e pró-atividade discente. 
Os outros eixos curriculares também podem ser sublinhados como estratégias que almejam contribuir na missão da UFPR Litoral. Tanto os FTP quanto as ICH podem ter interfaces com a sensibilização de problemas regionais e atuarem na busca da resolução, ou ao menos no questionamento e na problematização dessa conjuntura. O próprio desenho dos Cursos ofertados no campus também não foi feito aleatoriamente. Partiu de uma contextualização de algumas dessas vulnerabilidades regionais, como saúde, sazonalidade, educação, sócio-economia, mas também converge com a eleição de algumas potencialidades, como turismo, meio ambiente, manifestações culturais, etc.

Outro elemento significativo com vistas à diminuição dos problemas litorâneos é o Grupo de Articuladores da Educação Pública, que objetiva coligar os diferentes níveis de ensino público na região, articulando as Secretarias Municipais de Educação com a Universidade. O grupo conta com articuladores responsáveis respectivamente por cada um dos municípios, que servem de ligação entre o ensino público (da educação infantil, fundamental e médio) das esferas Municipais e Estadual, com o Ensino Superior, da esfera Federal. Essa articulação almeja concretização de ações que se traduzam em incrementos do nível educacional regional, acreditando que esse seja um dos alicerces para a materialização do desenvolvimento litorâneo.

Se por um lado, muitos êxitos podem ser destacados até aqui, como o ingresso de 70 a 80 \% dos estudantes provenientes da região; as políticas afirmativas, que permitem o acesso de grupos que teriam dificuldade de ingressar na Instituição; a disponibilidade de considerável número de bolsas de estudo, que contribui com a permanência de muitos estudantes na Universidade; assim como muitos casos de sucesso em torno da proposta narrados e documentados até aqui; por outro lado, muitos desafios também estão colocados. Os desafios existem na mesma proporção que os êxitos e são inerentes a qualquer idéia inovadora, que promova ruptura em modelos tradicionais. De acordo com os entrevistados, são assinalados como maiores desafios: a falta de experiências semelhantes, que forneçam subsídios comparativos e parâmetros de análise; a necessidade de criação de instrumentos que possam avaliar sistematicamente a experiência, que permitam apontar os futuros (re)direcionamentos da proposta; as limitações de diversas naturezas, que mereceriam ser pensadas com mais critérios; determinados hiatos existentes entre alguns discursos e práticas; entre outros.

Cabe ponderar, portanto, que a experiência da UFPR Litoral destaca-se por apresentar em seu bojo, uma proposta diferenciada, que vem veiculando contradições que se configuram 
em terreno fértil para a realização de mais pesquisas, como esta, e de outras, que avancem em outros aspectos. Com este estudo, aspirou-se promover uma reflexão acerca das estratégias e metodologias que vêm sendo tecidas na UFPR Litoral, com vistas à diminuição de problemas locais e contribuição com o Desenvolvimento Regional. Muitas indagações emergem com este trabalho, tais como: Como mensurar se a UFPR Litoral está promovendo realmente a minimização dos problemas locais? Em que medida a população regional está sendo realmente protagonista do planejamento e implementação de ações pertinentes ao incremento da Instituição? Quais as futuras possibilidades e novos horizontes para a proposta? Estas são algumas das questões que emergem e reclamam outras pesquisas e estudos na continuidade do processo aqui empreendido a título de uma breve e limitada circunscrição histórica, que pela sua permeabilidade e natureza busca outras construções.

\section{REFERÊNCIAS}

ALBUQUERQUE, R. C. A Universidade e o Nordeste. In: ANDRADE, A. C. (Org.). A Universidade e o Desenvolvimento Regional. Fortaleza: UFC, 1980.

BRIZOLLA, F. Educação como projeto de mudança social: relato de uma experiência de ampliação do sentido e do espaço público da educação a partir de políticas de cooperação entre Ensino Superior e educação básica. 2010. Trabalho apresentado ao I Congresso Ibero-Luso-Brasileiros de Política e Administração da Educação, Elvas - Portugal, 2010 .

FAGUNDES, M. C. V. Universidade e Projeto Político-Pedagógico: diálogos possíveis fomentando formações emancipatórias. 2009. 235f. Tese (Doutorado em Educação) Universidade do Vale do Rio dos Sinos - Unisinos, São Leopoldo.

FERNANDES, R. Impactos Locais e Regionais da Universidade do Porto. Dissertação de Mestrado em Economia, Faculdade de Economia, Universidade do Porto. 2007a. 136p.

FREIRE P. Pedagogia da autonomia: saberes necessários à prática educativa. São Paulo: Paz e Terra; 1996.

GUERREIRO, J. As funções da Universidade no âmbito dos sistemas de inovação. Rev. Sociedade e Trabalho, $N^{\circ}$ 28, pp. 51-61. 2006.

MATURANA, H. R.; VARELA, F.J. A árvore do conhecimento: as bases biológicas da compreensão humana. Mariotti H, Diskin L, Tradutores. São Paulo: Palas Athena; 2001.

MINAYO M. C. S; ASSIS S.G; SOUZA, E. R. Avaliação por triangulação de métodos: Abordagem de programas Sociais. Rio de Janeiro: Fio Cruz, 2005. 
MORAES, M. C. Educar na biologia do amor e da solidariedade. Petrópolis, RJ: Vozes, 2003.

MORIN, E. Epistemologia da complexidade. In: SCHNITMAN, D.F. (Org). Novos Paradigmas, cultura e subjetividade. Porto Alegre: Artes Médicas, 1996.

MORIN, E. A cabeça bem-feita: repensar a reforma, reformar o pensamento. $18^{a}$ Edição. Rio de Janeiro: Bertrand Brasil, 2010.

SIGNORELLI, M. C. et al . Um projeto político-pedagógico de graduação em fisioterapia pautado em três eixos curriculares. Revista Fisioterapia em movimento. (Impr.), Curitiba, v. 23, n. 2, Jun. 2010.

SILVA, M.I, SILVA, J. F. S. O sucateamento do ensino superior público brasileiro no contexto da crise globalizada contemporânea. Revista lentes pedagógicas. v.1 n.2, 2011.

SOUSA SANTOS, B. Um discurso sobre as ciências. 2 ed. São Paulo, SP: Cortez, 2004.

THERRIEN, J; CARTAXO, H. A Universidade e o Desenvolvimento Regional: elementos para um debate. In: ANDRADE, A. C. (Org.). A Universidade e o Desenvolvimento Regional. Fortaleza: UFC, 1980. cap. 1, p. 17-22.

UFPR. SETOR LITORAL. Projeto Político Pedagógico. Matinhos, 2008a. Disponível em: $<$ http://www.litoral.ufpr.br/pdfs/2009/PPP\%20-\%20UFPR\%20-

\%20LITORAL_Set 2008 Alteracao_Dez_2008_Impress\%E3o.pdf $>$ acessado 09/03/2011.

UFPR SETOR LITORAL. Trajetória da Implantação da UFPR Litoral. Matinhos, 2008b. $234 \mathrm{p}$.

UFPR - SETOR LITORAL. Cursos e Profissões. Matinhos, 2010. (livreto de divulgação institucional). 